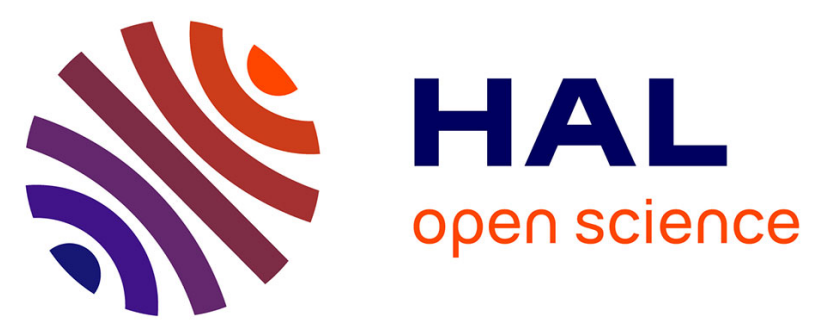

\title{
Charge storage properties of single wall carbon nanotubes/Prussian blue nanocube composites studied by multi-scale coupled electrogravimetric methods \\ Freddy Escobar-Teran, Hubert Perrot, Ozlem Sel
}

\section{- To cite this version:}

Freddy Escobar-Teran, Hubert Perrot, Ozlem Sel. Charge storage properties of single wall carbon nanotubes/Prussian blue nanocube composites studied by multi-scale coupled electrogravimetric methods. Electrochimica Acta, 2018, 271, pp.297-304. 10.1016/j.electacta.2018.03.140 . hal-01803191

\section{HAL Id: hal-01803191 \\ https://hal.sorbonne-universite.fr/hal-01803191}

Submitted on 30 May 2018

HAL is a multi-disciplinary open access archive for the deposit and dissemination of scientific research documents, whether they are published or not. The documents may come from teaching and research institutions in France or abroad, or from public or private research centers.
L'archive ouverte pluridisciplinaire HAL, est destinée au dépôt et à la diffusion de documents scientifiques de niveau recherche, publiés ou non, émanant des établissements d'enseignement et de recherche français ou étrangers, des laboratoires publics ou privés. 


\title{
Charge Storage Properties of Single Wall Carbon \\ Nanotubes/Prussian Blue Nanocube Composites Studied by Multi- scale Coupled Electrogravimetric Methods
}

\author{
F. Escobar-Teran, ${ }^{\mathrm{a}, \mathrm{b}}$ H. Perrot ${ }^{\mathrm{a}}$ and O. Sel ${ }^{\mathrm{a}}$
}

aSorbonne Université, CNRS, Laboratoire Interfaces et Systèmes Électrochimiques, LISE, F75005, Paris, France.

${ }^{\text {b} F a c u l t a d ~ d e ~ C i e n c i a ~ e ~ I n g e n i e r i ́ a ~ d e ~ A l i m e n t o s, ~ U n i v . ~ T e ́ c n i c a ~ d e ~ A m b a t o, ~ A v e n i d a ~ L o s ~}$ Chasquis y río Payamino s/n, Ambato, Ecuador.

Corresponding authors: hubert.perrot@upmc.fr and ozlem.sel@upmc.fr

\begin{abstract}
:
The gravimetric and dynamic aspects of the ions transfer at SWCNT/Prussian blue (PB) composite film electrode/electrolyte interface was investigated by the electrogravimetric impedance which couples fast quartz crystal microbalance (QCM) and electrochemical impedance spectroscopy (EIS). In contact with an aqueous $\mathrm{KCl}$ electrolyte, evidence was found that the kinetic of species is controlled by Faraday and capacitive electrochemical charge storage mechanisms. It was found that the interfacial transfer of $\mathrm{K}^{+}$was faster than the $\mathrm{Cl}^{-}$ transfer in the studied potential window. Through our electrogravimetric method of investigation, it was revealed that both adsorption/desorption and the insertion/expulsion phenomena can occur for $\mathrm{K}^{+}$, while only adsorption/desorption can occur for $\mathrm{Cl}^{-}$. Indeed, for pure PB films, the anion contribution to the charge compensation process has never been observed in the studied medium and for that, it is related to only electroadsorption on the SWCNT part of the film. Present work higlighted tha fact that electrogravimetric response of the SWCNT/PB composite electrode encloses several species contribution probably due to a synergic effect of the two phases and our study contributes to disentagling it both gravimetrically and dynamically.
\end{abstract}

Keywords: Single wall carbon nanotubes, Prussian blue, electrochemical quartz-crystal microbalance (EQCM), ac-electrogravimetry, charge storage. 


\section{Introduction}

Carbon nanotubes (CNTs) types (single-, double-, or multi-walled CNTs) are the materials the most investigated due for their high electrical conductivity, unique pore structure, chemical reactivity and thermal stability and relatively low equivalent series resistance (ESR) (lower than activated carbon) [1-3].

Although their surface area is relatively moderate compared to activated carbon, it may be used more efficiently due to the fact that the mesopores are interconnected, thus, providing access to nearly all the surface area and enabling a continuous distribution of charges [1-3]. Altogether, these properties make CNTs suitable for energy storage and conversion applications including batteries, fuel cells and supercapacitors [4-11].

However, there are studies that indicate that CNTs have limitations $[9,12]$ as well as advantages [13]. Therefore, an alternative is the use of materials composed of different compositions that combine the beneficial aspects and compensate the limitations of each one of the compositions, as is the case of composite materials [14,15]. Particularly, nanocomposite electrodes of CNTs and conducting polymers have been widely studied the last few years to improve the specific capacitance of the supercapacitors [4,16-20].

Prussian blue (PB) is a material widely studied due to its interesting electrochromic, electronic, redox and photo magnetic properties. PB presents many potential applications in electrocatalysis, sensors, rechargeable batteries, electrochromic devices and photomagnetism $[13,21-23]$

PB films can be regenerated either chemically [21,24] or electrochemically [25], often from an aqueous solution of a mixture of $\mathrm{FeCl}_{3}$ and $\mathrm{K}_{3} \mathrm{Fe}(\mathrm{CN})_{6}$. The freshly deposited $\mathrm{PB}$ films are in the "insoluble" form, $\mathrm{Fe}_{4}\left[\mathrm{Fe}(\mathrm{CN})_{6}\right]_{3}$ and after several voltammetric cycles in $\mathrm{KCl}$ solution, they are converted into the "soluble" structure, which is characterized by the presence of potassium substituting for $1 / 4$ of the high-spin iron sites in the "insoluble" PB structure 
$\left(\mathrm{KFeFe}(\mathrm{CN})_{6}\right)$. Prussian Blue films can be reduced to the colorless form, called Everitt's salt $\left(\mathrm{KFe}_{4}\left[\mathrm{Fe}(\mathrm{CN})_{6}\right]_{3}\right.$ or $\left.\mathrm{K}_{2} \mathrm{FeFe}(\mathrm{CN})_{6}, \mathrm{ES}\right)$, or oxidized to the yellow form called Prussian Yellow $\left(\mathrm{Fe}_{4}\left[\mathrm{Fe}(\mathrm{CN})_{6}\right]_{3} \mathrm{Cl}\right.$ or $\left.\mathrm{KFeFe}(\mathrm{CN})_{6} \mathrm{Cl}, \mathrm{PY}\right)$. The reduction process for the "soluble" $\mathrm{PB}$ structure has been described as follows [22]:

$$
\mathrm{KFe}^{\mathrm{III}} \mathrm{Fe}^{\mathrm{II}}(\mathrm{CN})_{6}+\mathrm{e}^{-}+\mathrm{K}^{+} \underset{\mathrm{k}_{\mathrm{c}}^{\prime}}{\stackrel{\mathrm{k}_{\mathrm{c}}}{\rightleftarrows}} \mathrm{K}_{2} \mathrm{Fe}^{\mathrm{II}} \mathrm{Fe}^{\mathrm{II}}(\mathrm{CN})_{6}(1)
$$

where $\mathrm{Fe}^{\mathrm{III}}$ and $\mathrm{Fe}^{\mathrm{II}}$ refer to the different oxidation states of $\mathrm{Fe}$ atoms in the PB structure.

PB films in $\mathrm{KCl}$ solutions have been widely studied in the past years by electrochemical impedance and cyclic voltammetry [26-28]. However, many aspects about the electrochemical behavior of these films have not still been clarified, especially the insertion/expulsion phenomena of ions/solvent within the film.

Therefore, PB films have also been studied by electrochemical quartz crystal microbalance (EQCM) because this technique provides significant information concerning the mass changes of ions within the film $[26,29,30]$. In this technique, the changes of the mass deposited on the gold electrode, $\Delta m$, are related to changes in the resonance frequency of the quartz crystal, $\Delta f_{m}$, by means from equation of Sauerbrey [31]:

$$
\Delta \mathrm{f}_{\mathrm{m}}=-\mathrm{k}_{\mathrm{s}} \mathrm{x} \Delta \mathrm{m}=-\left(\frac{2 \mathrm{f}_{0}^{2}}{\operatorname{Sn} \sqrt{\rho_{\mathrm{q}} \mu_{\mathrm{q}}}}\right) \Delta \mathrm{m}
$$

where $\rho_{q}$ is the quartz density $\left(2.648 \mathrm{~g} . \mathrm{cm}^{-3}\right), \mu_{q}$ is the shear modulus of a shear AT quartz crystal $\left(2.947 \times 10^{11} \mathrm{~g} \mathrm{~cm}^{-1} \mathrm{~s}^{-2}\right), f_{0}$ is the fundamental resonant frequency of the quartz $(\mathrm{Hz}), S$ is the active surface on the quartz corresponding to the metal electrode deposited on it $\left(\mathrm{cm}^{2}\right), n$ is the overtone number and $k_{\mathrm{s}}$ is the theoretical sensitivity factor $\left(\mathrm{Hz} \mathrm{g}^{-1} \mathrm{~cm}^{2}\right)$. It has been demonstrated that the equation of Sauerbrey is valid for this thickness of PB films. Thus, mass changes from frequency changes can be obtained [30]. 
The remarkable sensitivity of the EQCM technique has attracted particular attention in the energy storage community (supercapacitors, Li-ion and Na-ion batteries) since "discrete" events like inter-calation and/or electroadsorption of ions, surface film formation (SEI) or dissolution of active materials can be detected [32-40].

CNT/PB Nanocomposite has been another material studied for applications in sensors [41], battery components [42], and electrochromic devices [43] due to interesting properties. Recently Nossol et al studied the electrochemical behavior of CNT/PB nanocomposite in $\mathrm{KCl}$ aqueous solution using electrochemical techniques including the EQCM, and scanning electrochemical microscopy (SECM). The authors confirm with these techniques that $\mathrm{KCl}$ participates as electrolyte support in PB formation and the redox activity takes place at both metallic centers in PB [13]. Furthermore, the authors suggest that the nanocomposite material provide a potentially useful material for applications in optical devices and as cathode for flexible and transparent potassium ion battery [42]. However, the kinetic or dynamic aspects of the ion insertion/expulsion, as well as the role of the electrolyte composition and the effect of ions solvation during electrochemical processes have not explained in details with these kind of techniques.

Here, an alternative and complementary characterization tool to classical EQCM was proposed which couples the fast quartz crystal microbalance (QCM) and electrochemical impedance spectroscopy (EIS) (also called ac-electrogravimetry) [44-53]. Ac-electrogravimetry has proved itself for its utility to discriminate the activity of the different species involved in the charge transfer during an electrochemical process. More precisely, it provides access to relevant information on the kinetics of species transferred at the electrode/electrolyte interface and their transport in the bulk of the materials, the nature of these species as well as their relative concentration within the material. Consequently, ac-electrogravimetry has been used as a relevant tool for studying the nature of the ionic flux at the electrode/electrolyte interface for 
many systems such as conducting polymers [45], metal oxides [46-47] and carbon based electrodes $[50,53]$. Here, in this study, it has been used for the first time to study a composite material and permitted the synergic effect of the CNTs together with a redox active material on the charge storage behavior of the composite electrode to be investigated.

\section{Theoretical background for ac-electrogravimetry}

The change of the concentration, $\Delta C_{i}$, of each species (ex. $i=$ cation1 (c1) and cation2 (c2), and anion (a), and free solvent (s)) over a potential $\Delta E$ step can be estimated using Eq. (3):

$$
\left.\frac{\Delta C_{i}}{\Delta E}\right|_{t h}(\omega)=\frac{-G_{i}}{j \omega d+K_{i}}
$$

where $\omega=2 \pi f$ is the pulsation, $f$ is the frequency of potential modulation and $K_{i}$ and $G_{i}$ are the partial derivatives of the flux with respect to the concentration and the potential, respectively. $K_{i}$ is related to the kinetics of the ionic or free solvent transfer. $G_{i}$ is the inverse of the transfer resistance, $R_{t_{i}}=\frac{1}{F G_{i}}$, of the species at the film/electrolyte interface [44-53].

The charge/potential transfer function, $\left.\frac{\Delta q}{\Delta E}\right|_{t h}(\omega)$, calculated for the transfer of two cations, $c 1$ and $c 2$, and an anion, $a$, using the Faraday number, $F$ and the film thickness, $d_{f}$ can be written as follows :

$$
\left.\frac{\Delta q}{\Delta E}\right|_{t h}=d_{f} F\left(\frac{G_{c 1}}{\left(j \omega d_{f}\right)+K_{c 1}}-\frac{G_{c 2}}{\left(j \omega d_{f}\right)+K_{c 2}}-\frac{G_{a}}{\left(j \omega d_{f}\right)+K_{a}}\right)
$$

The theoretical electrogravimetric transfer function, $\left.\frac{\Delta m}{\Delta E}\right|_{t h}(\omega)$, can be calculated, taking into account the charged/uncharged species contribution: 
$\left.\frac{\Delta m}{\Delta E}\right|_{t h}(\omega)=d_{f}\left(m_{c 1} \frac{\Delta G_{c 1}}{\left(j \omega d_{f}\right)+K_{c l}}+m_{c 2} \frac{\Delta G_{c 2}}{\left(j \omega d_{f}\right)+K_{c 2}}+m_{a} \frac{\Delta G_{a}}{\left(j \omega d_{f}\right)+K_{a}}+m_{s} \frac{\Delta G_{S}}{\left(j \omega d_{f}\right)+K_{S}}\right)$

where $m_{c l}, m_{c 2}, m_{a}$ and $m_{s}$ are the atomic weight of involved species.

From the theoretical overall electrogravimetric transfer function (4), it is possible to calculate the theoretical partial transfer functions by removing the $c 2$ contribution, calculating $\left.\frac{\Delta m}{\Delta E}\right|_{t h} ^{\text {clas }}(\omega)$; or the $c l$ contribution, calculating; $\left.\frac{\Delta m}{\Delta E}\right|_{t h} ^{\text {c2as }}(\omega)$ or the anion contribution, calculating $\left.\frac{\Delta m}{\Delta E}\right|_{t h} ^{c l c 2 a s}(\omega)$; as shown in the following equations:

$$
\begin{aligned}
& \left.\frac{\Delta m}{\Delta E}\right|_{t h} ^{c l a s}(\omega)=-d_{f}\left[\left(m_{c 1}-m_{c 2}\right) \frac{\Delta C_{c 1}}{\Delta E}+\left(m_{a}+m_{c 2}\right) \frac{\Delta C_{a}}{\Delta E}+m_{s} \frac{\Delta C_{S}}{\Delta E}\right] \\
& \left.\frac{\Delta m}{\Delta E}\right|_{t h} ^{c 2 a s}(\omega)=d_{f}\left[\left(m_{c 2}-m_{c 1}\right) \frac{\Delta C_{c 1}}{\Delta E}+\left(m_{a}+m_{c 1}\right) \frac{\Delta C_{a}}{\Delta E}+m_{S} \frac{\Delta C_{S}}{\Delta E}\right] \\
& \left.\frac{\Delta m}{\Delta E}\right|_{t h} ^{c l c 2 s}(\omega)=d_{f}\left[\left(m_{c 1}+m_{a}\right) \frac{\Delta C_{c 1}}{\Delta E}+\left(m_{c 2}+m_{a}\right) \frac{\Delta C_{c 2}}{\Delta E}+m_{S} \frac{\Delta C_{S}}{\Delta E}\right]
\end{aligned}
$$

\section{Experimental}

Single Wall CNT (755117-1G, length: 300-2300 nm and diameter: 0.7-1.1 nm) and potassium hexacyanoferrate(III) (99.98\% trace metals basis) were acquired from Sigma Aldrich. The preparation of the SWCNT thin layers on the gold electrode (effective surface area of $0.20 \mathrm{~cm}^{2}$ ) of a quartz crystal resonator (9 MHz -AWS, Valencia, Spain) was previously described [50]. The subsequent synthesis of the SWCNT/PB nanocomposite films were carried out according to the method reported by Nossol et al [13]. The procedure consists of cycling the SWCNT coated quartz resonator in a solution containing $1 \times 10^{-3} \mathrm{M} \mathrm{K}_{3} \mathrm{Fe}(\mathrm{CN})_{6}$ and $0.1 \mathrm{M} \mathrm{KCl}$ at a scan rate of $0.05 \mathrm{~V} \mathrm{~s}^{-1}$ in a potential range from $-0.2 \mathrm{~V}$ to $0.8 \mathrm{~V} v s \mathrm{Ag} / \mathrm{AgCl}$ during 15 cycles. 
EQCM measurements were performed in an aqueous solution of $0.5 \mathrm{M} \mathrm{KCl}$ at $\mathrm{pH}=3$. A platinum grid and $\mathrm{Ag} / \mathrm{AgCl}$ were used as counter electrode and as reference electrode, respectively. The gravimetric regime was assured by keeping film thickness acoustically thin $(<500 \mathrm{~nm})$ as it was mentioned previously in the introduction part [30].

For $a c$-electrogravimetry, a four-channel frequency response analyzer (FRA, Solartron 1254) and a lab-made potentiostat (SOTELEM-PGSTAT) were used. The QCM was used under dynamic regime, the working electrode (WE) was polarized at a selected potential, and a sinusoidal small amplitude potential perturbation $(60 \mathrm{mV} \mathrm{rms})$ was superimposed. The microbalance frequency change, $\Delta f_{m}$, corresponding to the mass response, $\Delta m$, of the WE was measured simultaneously with the $a c$ response, $\Delta I$, of the electrochemical system. The frequency range was between $63 \mathrm{kHz}$ and $10 \mathrm{mHz}$. The resulting signals were sent to the fourchannel FRA, which allowed the electrogravimetric transfer function (TF), $\frac{\Delta m}{\Delta E}(\omega)$, and the electrochemical impedance, $\frac{\Delta E}{\Delta I}(\omega)$, to be simultaneously obtained at a given potential [4446]. The measurements were performed in $0.5 \mathrm{M} \mathrm{KCl}$ at $\mathrm{pH}=3$ and at every $100 \mathrm{mV}$ in the following potential range: $-0.45 \mathrm{~V}-0.45 \mathrm{~V}$ ss $\mathrm{Ag} / \mathrm{AgCl}$.

\section{Results and discussion}

\subsection{Structure and morphology of the SWCNT/PB nanocube composite thin films}


The surface morphology of the SWCNT/PB nanocomposite thin films deposited on the gold electrode of the quartz resonators were characterized by FEG-SEM. Prussian blue was deposited on the SWCNTs via cyclic voltammetry. After 15 cycles, nanosized cubes were formed and distributed along the thin layer of SWCNT films (Figure 1A and B), which corresponds to Prussian Blue (PB).

The EDX analysis coupled with FEG-SEM observations indicates the presence of both $\mathrm{C}$ and $\mathrm{Fe}$ as constituents of the SWCNT/PB composite (See Figure 2A and B). The presence of Au and Si peaks is due to the gold electrode of the QCM and the quartz itself, respectively. The observation of $\mathrm{K}$ and $\mathrm{N}$ related peaks further confirms the formation of $\mathrm{PB}$ on the CNTs where the $\mathrm{PB}$ structure is $\mathrm{KFe}^{\mathrm{III}} \mathrm{Fe}^{\mathrm{II}}(\mathrm{CN})_{6}$.

\subsection{EQCM study of the SWCNT/PB nanocube composite films}

Figure 3 shows the current and mass changes of the SWCNT/PB film when it is oxidized and reduced between $-0.45 \mathrm{~V}$ and $0.45 \mathrm{~V} v s \mathrm{Ag} / \mathrm{AgCl}$ at a scan rate of $50 \mathrm{mV} \mathrm{s}^{-1}$ in a $0.5 \mathrm{M} \mathrm{KCl}$ solution ( $\mathrm{pH}$ 3). The cyclic voltammetry in Figure 3 presents a capacitive behavior between $0.45 \mathrm{~V}$ to $-0.15 \mathrm{~V}$ (zone I) and $0.2 \mathrm{~V}$ to $0.45 \mathrm{~V}$ (Zone III), which is typical for the electrochemical response of SWCNT films [50]. In the range of $\sim 0.05 \mathrm{~V}$ to $\sim 0.15 \mathrm{~V}$ (Zone II), peaks of oxidation/reduction are observed, which corresponds to the characteristic PB redox response. Therefore, the CV responses of the composite films show the electrochemical signatures of the both components with higher current values than that obtained for pure PB $[30,44,49]$ and SWCNT thin film electrodes [50]. Accordingly, the mass changes of the composite films are also enhanced compared to the pure PB $[44,49]$ and SWCNT thin film electrodes [50].

The SWCNT/PB electrode presents a particular behavior regarding the mass response (Figure 3). A main contribution of cations in the zone of $-0.45 \mathrm{~V}$ to $-0.15 \mathrm{~V}$ (Zone I) and of anions in the zone of $0.2 \mathrm{~V}$ to $0.45 \mathrm{~V}$ (Zone III) can be attributed to the electroadsorption/electrodesorption of 
cations and anions at the SWCNT/electrolyte interfaces, when the surface is negatively and positively charged, respectively. The Zone II presents a mass decrease and increase during an anodic to cathodic and a cathodic to anodic scan, respectively. If the composite thin film behaved like a pure PB film in the Zone II, the mass response would be the opposite of that observed in Figure 3 i.e. reduction/oxidation of the PB structure is accompanied by the insertion/desinsertion of the cations for the charge compensation purposes [30,44,49]. This anomalous behavior in mass change in Zone II may indicate the cooperative behavior of the SWCNT and the PB components which may lead to the global mass response in Figure 3.

These results are corroborated to the molar mass of the species transferred at the interfaces by the calculation of the $\mathrm{F} \frac{\Delta m}{\Delta Q}(\omega)$ function. Figure 4 shows the variation of $\mathrm{F} \frac{\Delta m}{\Delta Q}(\omega)$ values as a function of the potential applied, obtained from the reduction branch of the EQCM data in Figure 3, in the range $0.4 \mathrm{~V}$ to $-0.4 \mathrm{~V}$ vs $\mathrm{Ag} / \mathrm{AgCl}$ measured in $0.5 \mathrm{M} \mathrm{KCl}$. Three zones are defined: (i) Zone I, between $-0.4 \mathrm{~V}$ to $0.1 \mathrm{~V}$, the species involved could be the hydrated $\mathrm{K}^{+}$, (ii) Zone II, range $-0.1 \mathrm{~V}$ to $0.15 \mathrm{~V}$, the species involved could be $\mathrm{K}^{+}$and $\mathrm{H}_{3} \mathrm{O}^{+}$which is coherent with the PB response (reaction I) and (iii) Zone III, range $0.15 \mathrm{~V}$ to $0.4 \mathrm{~V}$, the species involved could be $\mathrm{Cl}^{-}$but the high values (in g. $\mathrm{mol}^{-1}$ ) estimated indicate the contribution of the free solvent.

The capacitance was calculated by using the following relation: $C_{\text {specific }}(F / g)=\frac{I(\text { Amper })}{v_{S}(\text { volt } / \text { second }) \times \text { electrode mass }(g)}$, where $C$ is the specific capacitance, $I$ is the measured current and $v_{s}$ is the scan rate used. The capacitance values of the thin films were normalized with precision thanks to the exact determination of the film mass using the QCM. These measurements were performed by comparing the resonance frequency of the resonator before and after the film elaboration. The capacitance values are estimated to be around $25 \mathrm{~F} \mathrm{~g}^{-}$ ${ }^{1}$ in the zones III and I, which is in good agreement with the values obtained in the literature 
[4]. The capacitance value of the oxidation peak (PB active zone is estimated to be around 250 $\mathrm{F}^{-1}$ (Figure SI in the Supporting Information). Another method for the calculation of the capacitance adapted to faradaic process has been proposed using the following relation $C=\frac{\int_{E_{2}}^{E_{1}} i(E) d E}{2\left(E_{2}-E_{1}\right) m v}$ where $C$ is the specific capacitance of electrode, $E_{1}$ and $E_{2}$ are the working voltage in cyclic voltammetry, and $\int_{E_{2}}^{E_{1}} i(E) d E$ is the total voltammetric charge in cyclic voltammetry, $m$ is the mass of the film, and $v$ is the scan rate. The value is estimated to be around $114 \mathrm{~F} \mathrm{~g}^{-1}$ which is four times higher than the capacitance values obtained in the literature for the SWCNT thin films [4]. This improvement in capacitance is due to the faradaic process that occurs in the redox zone.

\subsection{Ac-electrogravimetric study of the SWCNT/PB nanocube composite films}

The measurements were performed at each $100 \mathrm{mV}$ in the range from $-0.4 \mathrm{~V}$ to $0.4 \mathrm{~V} v s$ $\mathrm{Ag} / \mathrm{AgCl}$. Figure 5 and 6 show an example of the experimental and theoretical transfer functions (TFs) obtained from $a c$-electrogravimetry of a SWCNT/PB thin film in $0.5 \mathrm{M} \mathrm{KCl}$ electrolyte at $-0.1 \mathrm{~V}$ vs $\mathrm{Ag} / \mathrm{AgCl}$. The experimental data were fitted according to the models presented in previous investigations [44,50]. Figure 5 and 6 reveal a good agreement between experimental data and theoretical curves. First, the electrochemical impedance $\frac{\Delta E}{\Delta I}(\omega)$ responses (Figure 5A) present a slightly distorted straight line indicating that there is a multi-ion transfer contribution. Consequently, it is difficult to extract information. However, it should be noted that there is no evident part with a slope equal to $45^{\circ}$ or below in the electrochemical impedance response, therefore, the rate limiting step is not the mass transport in the films or in the solution, but rather the ionic transfer between the solution and the film [44].

The charge/potential transfer functions (TFs), $\frac{\Delta q}{\Delta E}(\omega)$ (Figure 5B), permit the separation of the ionic contributions, however, without any possibility to identify the ionic species involved. 
Figure 5B shows one big loop at the high frequencies and a smaller contribution at the low frequencies. They can be attributed to any of the ionic species present in the electrolyte and their time constants are not sufficiently different from each other (otherwise they would appear as two completely separate loops). The simulation of the experimental data indicates the contribution of the three ionic species; the big loop at higher frequency is composed of two ionic species response with a third ionic species which contributes at the lower frequency region. The mass/potential TF permits the identification of these ionic species (also solvent molecules if there is any), especially when it is associated to partial TFs.

In the mass/potential transfer function $\frac{\Delta m}{\Delta E}(\omega)$ (Figure 6A), one big loop appears in the third quadrant. The loops in the third quadrant are characteristic for cation contributions or free solvent molecules in the same flux direction. Another contribution also appears at lower frequencies in the fourth quadrant (anions with opposite flux direction) highlighting the challenge in the exact identification of these two or three loops. The fitting of the experimental data by Mathcad software, using the equation 5 showed the presence of three charged species: $\mathrm{K}^{+}$at higher frequencies, $\mathrm{H}^{+}$at intermediate frequencies and $\mathrm{Cl}^{-}$at lower frequencies which confirms the configuration given by the $\frac{\Delta q}{\Delta E}(\omega)$ TF in Figure 5B. Another contribution to the mass response at intermediate frequencies was also detected which is attributed to the free solvent. The identification of these species was achieved by the determination of their molar mass using Equation 4. Their respective kinetics of transfer were determined by the $K_{i}$ values. The presence of three different ionic species and free solvent molecules contribution estimated by simulating the experimental data was further confirmed by a fair analysis of the partial electrogravimetric transfer functions, for example, by removing the $c 2$ contribution and calculating $\left.\frac{\Delta m}{\Delta E}\right|_{t h} ^{\text {clas }}(\omega)$, by removing the $c 1$ contribution and calculating $\left.\frac{\Delta m}{\Delta E}\right|_{t h} ^{c 2 a s}(\omega)$ or the 
anion contribution, calculating $\left.\frac{\Delta m}{\Delta E}\right|_{t h} ^{c l c 2 a s}(\omega)$ (Equations 6,7 and 8). The panels in Figure 6 B$\mathrm{C}$ exhibit a good agreement between the theoretical and experimental data. This partial electrogravimetric transfer function provides a crosscheck for validating the hypothesis involving four different species and allowing a better separation of the various contributions to be attained. The $a c$-electrogravimetry results at two other potentials situated in the Zone I and Zone II (indicated in Figure 3) are given in the Supporting Information. Figure SII and SIII shows the results from the cathodic region (at $-0.4 \mathrm{~V}$ ) which indicates the contribution of the two different cations $\left(\mathrm{K}^{+}\right.$and $\left.\mathrm{H}^{+}\right)$which is attributed to the capacitive charge storage in the SWCNT component of the SWCNT/PB nanocubes composite and in agreement with our earlier work [50]. The results of a potential situated in the Zone III (Figure SIV) indicate the presence of both $\mathrm{K}^{+}$and $\mathrm{Cl}^{-}$ions where the latter is attributed to the capacitive charge storage in SWCNT since the PB is known to be a pure cation exchanger [44].

The same fitting procedure and validation process were used for all the other potentials and the pertinent parameters $\left(K_{i}, G_{i}\right.$ and $\left.R_{t_{i}}=\frac{1}{F G_{i}}\right)$ for all the species transferred were estimated. Figure 7 shows the evolution of transfer kinetics, $K_{i}$, and the transfer resistance, $R t_{i}$, of the species as a function of the potential applied. This potential range corresponds to the conditions where the electroadsorption/desorption and insertion/expulsion process of the composite thin film are observed. Based on the $K_{i}$ values presented in Figure $7 \mathrm{~A}$, the $\mathrm{K}^{+}$ion is the fastest of the three species. Furthermore, the transfer kinetics of free water molecules are somewhat close to the values of the $\mathrm{K}^{+}$ion. Additionally, these water molecules have the same flux directions as the cations, suggesting that these might be the water molecules that accompany the transfer of $\mathrm{K}^{+}$, most likely due to an electrodragging process. Chloride anions appear only for the more anodic potentials which indicate that the capacitive CNT film behavior is dominant in this potential range. If we compare the $\mathrm{K}^{+}$ions' kinetics of the composite film with that observed 
in pristine SWCNTs, one can say that the presence of PB on the surface of SWCNTs does not slow down the transfer dynamics of $\mathrm{K}^{+}$ions (similar $K_{i}$ in SWCNTs) [50]. Therefore, the enhanced capacitance value obtained for the composites in the presence of the PB nanocubes does not have a penalty in terms of dynamics of transfer.

Additionally, the contribution of potassium ions in the composite film is enlarged to the whole potential range (Figure 7A). For free solvent molecules, the transfer resistance value is smaller for the extreme potential values but in the PB electroactivity domain, this value becomes higher: $\mathrm{H}_{2} \mathrm{O}$ is more difficult to be transferred in the redox PB domain compared to potassium ions. Indeed, when only PB films are examined, free water molecules were not detected which is in line with the present observations $[44,51]$.

The transfer kinetic rates of $\mathrm{H}^{+}$in the SWCNT/PB are higher than the transfer kinetic rates of $\mathrm{H}^{+}$in pure SWCNT [50,52] probably due to the difference in $\mathrm{pH}$ (lower in this work) (Figure $6 \mathrm{~A}$ ), as a result, their transfer is easier than those in pure SWCNT (Figure 7B).

Considering the transfer resistance $\left(R t_{i}\right)$ values of ions, the $\mathrm{K}^{+}$in the SWCNT-PB are equivalent to the $\mathrm{K}^{+}$in the pure SWCNT [50,52]. As mentioned previously, in SWCNT/PB the transfer kinetic rates of $\mathrm{K}^{+}$is equivalent to that of $\mathrm{K}^{+}$in the pure SWCNT [50,52], thus advantageously, the presence of PB does not hinder the electroadsorption process of cations.

In order to quantify the role of each species, $\left.\frac{\Delta C_{i}}{\Delta E}\right|_{\omega \rightarrow 0}=-\frac{G_{i}}{K_{i}}$ has been calculated as a function of the applied potential. The integration of the $\left.\frac{\Delta C_{i}}{\Delta E}\right|_{\omega \rightarrow 0}$ against potential gives the relative concentration change, $\left(C_{i}-C_{0}\right)$. Figure 8 shows the relative concentration change for the ionic species involved in the electrochemical process. The $C_{i}-C_{0}$ values for $\mathrm{H}_{2} \mathrm{O}$ are significantly higher than the $\left(C_{i-} C_{0}\right)$ values of $\mathrm{K}^{+}$and $\mathrm{Cl}^{-}$, especially at more anodic potentials. Furthermore, all the species show different behaviors probably related to the composite structure: at more cathodic potentials, the concentration of $\mathrm{K}^{+}$increases in the studied potential window and the 
anions are not detected beyond $-0.1 \mathrm{~V} v s . \mathrm{Ag} / \mathrm{AgCl}$. The potassium species are detected at all potentials indicating a collective effect of the composite structure, i.e. potassium species due to the redox of PB and the electroadsorption on SWCNTs. The anions are detected only at anodic potentials indicating that they are related to the electroadsorption process on SWCNTs. The free water molecules accompany the potassium ions at cathodic potentials, but at more anodic potentials, the concentration of $\mathrm{H}_{2} \mathrm{O}$ and $\mathrm{Cl}^{-}$increases. These behaviors are probably due to the mixed Faradaic and non-Faradaic mechanisms of the charge storage of the composite film. As a comparison, we have detected that the $C_{i-} C_{0}$ values of the species $\mathrm{K}^{+}, \mathrm{Cl}^{-}$and free solvent are more significant in the composite SWCNT-PB thin films than in pristine SWCNT thin films. Furthermore, the $C_{i}$ - $C_{0}$ values of the free solvent in the SWCNT-PB are also higher and equivalent, at anodic potentials, and cathodic potentials, respectively, as compared to the pristine SWCNT thin films $[50,52]$. These results indicate that the relative concentration of the species is significantly increased in the case of the SWCNT/PB composite structure, which probably is the reason for the significantly higher specific capacitance values given previously (Figure SI).

\section{Conclusions}

The electrochemical charge storage properties of composite SWCNT/PB films was first assessed by classical cyclic electrogravimetry (EQCM), which was performed in $0.5 \mathrm{M}$ aqueous $\mathrm{KCl}$ electrolyte, from $0.45 \mathrm{~V} v s \mathrm{Ag} / \mathrm{AgCl}$ to $-0.45 \mathrm{~V} v s \mathrm{Ag} / \mathrm{AgCl}$. The specific capacitance of the film, the mass change and the $\mathrm{F} \frac{\Delta m}{\Delta Q}(\omega)$ function were calculated as a function of the potential. The SWCNT/PB film shows a capacitive behavior in the CNT zone (I and III) and a redox behavior in the mixed CNT/PB zone (II). Regarding the gravimetric analysis, even after the $\mathrm{F} \frac{\Delta m}{\Delta Q}(\omega)$ calculations, it is rather difficult to disentangle the various electrochemical reactions constituting the global response. For that reason, and to be able to characterize the EQCM 
response in depth, an ac-electrogravimetric study was performed in the same media under a sinusoidal potential perturbation. Experimental data were fitted using a theoretical model to find the kinetic parameters and to identify the contribution of the species, charged or non charged, involved in the charge compensation process. It was found out that the transfer of $\mathrm{K}^{+}$ was faster than the transfer of $\mathrm{Cl}^{-}$in the studied potential window. Through our electrogravimetric method of investigation, it was revealed that both the adsorption/desorption and the insertion/expulsion phenomena occur for $\mathrm{K}^{+}$, while only adsorption/desorption occurs for $\mathrm{Cl}^{-}$. Indeed, for pure PB films, the anion contribution was never seen and for that, is related to only electroadsorption. For the cathodic potentials, the proton contributions was also detected as in the case of the pure SWCNTs films in the same electrolyte. These findings suggest that the different sites for electroadsorption/insertion on the composite electrode are likely to remain accessible. Our electrogravimetric methodology, due to its temporal resolution and sensitivity has contributed to disentangle the complex charge storage behavior of SWCNT/PB composite electrode both gravimetrically and dynamically.

\section{AUTHOR INFORMATION}

Corresponding Authors: E-mail: ozlem.sel@upmc.fr (O. Sel), hubert.perrot@upmc.fr (H. Perrot)

\section{Supporting Information}

Supporting information available showing further electrochemical data (specific capacitance and $a c$-electrogravimetry) of the SWCNT/PB composite films.

\section{Acknowledgments}

F. Escobar-Teran thanks the SENESCYT for the financial support during his Ph.D. thesis. F. Pillier is thanked for the FEG-SEM measurements.

\section{References}


[1] E. Frackowiak, F. Beguin, Carbon materials for the electrochemical storage of energy in Capacitors, Carbon 39 (2001) $937-950$.

[2] J. Yan, Q.Wang, T. Wei, Z. Fan, Recent Advances in Design and Fabrication of Electrochemical Supercapacitors with High Energy Densities, Adv. Energy Mater. (4) 2014 $13008161-43$.

[3] M.Q. Zhao, C.E. Ren, Z. Ling, M.R. Lukatskaya, C. Zhang, K.L. Van Aken, M. W. Barsoum, Y. Gogotsi, Flexible MXene/Carbon Nanotube Composite Paper with High Volumetric Capacitance, Adv. Mat. 27 (2015) 339-345.

[4] H. Pan, L. Li, Y. Feng, Carbon Nanotubes for Supercapacitors, Nanoscale Res. Lett. 5 (2010) 654-668.

[5] D.S. Su, R. Schlögl, Nanostructured carbon and carbon nanocomposites for electrochemical energy storage applications, ChemSusChem 3 (2010) 136-168.

[6] P.L. Taberna, G. Chevallier, P. Simon, D. Plée, T. Aubert, Activated carbon-carbon nanotube composite porous film for supercapacitor applications, Materials Research Bulletin $2006,41,478$.

[7] M. Sevilla, R. Mokaya, Energy storage applications of activated carbons: supercapacitors and hydrogen storage, Energy \& Environmental Science 7 (2014) 1250-1280. [8] J. Huang, B.G. Sumpter, V. Meunier, Theoretical model for nanoporous carbon supercapacitors, Angew. Chem. Int. Ed. 47 (2008) 520-524.

[9] B.K. Kim, S. Sy, A. Yu, J. Zhang, Electrochemical Supercapacitors for Energy Storage and Conversion, in: J. Yan (Eds.), Handbook of Clean Energy Systems; John Wiley \& Sons, 2014. DOI: 10.1002/9781118991978.hces112

[10] V.V. Obreja, Supercapacitors Specialities - Materials Review, Review on Electrochemical Storage Materials and Technology AIP Conf. Proc. 1597 (2014) 98-120. https://doi.org/10.1063/1.4878482. 
[11] A. Borenstein, O. Hanna, R. Attias, S. Luski, T. Brousse, D. Aurbach, Carbon-based composite materials for supercapacitor electrodes: a review, J. Mater. Chem. A 5 (2017) 1265312672.

[12] L. Hu, D.S. Hecht, G. Gruener, Carbon Nanotube Thin Films: Fabrication, Properties, and Applications, Chem. Rev. 110 (2010) 5790-5844.

[13] E. Nossol, A.B. Nossol, S. Abdelhamid, L.L. Martin, A.J.G. Zarbin, A.M. Bond, Mechanistic insights gained by monitoring carbon nanotube/Prussian blue nanocomposite formation with in situ electrochemically based techniques, J. Phys. Chem. C 118 (2014) 1315713167.

[14] C. Peng, S. Zhang, D. Jewell, G.Z. Chen, Carbon nanotube and conducting polymer composites for supercapacitors, Prog. Nat. Sci. 18 (2008) 777-788.

[15] T. Bordjiba, D. Belanger, Direct Redox Deposition of Manganese Oxide on Multiscaled Carbon Nanotube/Microfiber Carbon Electrode for Electrochemical Capacitor, J. Electrochem. Soc. 150 (2009) A378-A384.

[16] K.H. An, K.K. Jeon, J.K. Heo, S.C. Lim, D.J. Bae, Y.H. Lee, High-Capacitance Supercapacitor Using a Nanocomposite Electrode of Single-Walled Carbon Nanotube and Polypyrrole, J. Electrochem. Soc. 149 (2002) A1058-A1062.

[17] H. Lin, L. Li, J. Ren, Z. Cai, L. Qiu, Z. Yang, H. Peng, Conducting polymer composite film incorporated with aligned carbon nanotubes for transparent, flexible and efficient supercapacitor, Scientific Reports 3:1353 (2013) 1-6.

[18] J.J. Chen, Q. Zhang, Y. Shi, L. Qin, Y. Cao, M. Zheng, Q. Dong, A hierarchical architecture S/MWCNT nanomicrosphere with large pores for lithium sulfur batteries. Phys. Chem. Chem. Phys. 14 (2012) 5376-5382.

[19] D.H. Kim, J. Song, W.M. Choi, H.S. Kim, R.H. Kim, Z. Liu, Y.Y. Huang, K.C. Hwang, Y. Zhang, J. Rogers, Materials and noncoplanar mesh designs for integrated circuits with linear 
elastic responses to extreme mechanical deformations, J. A. Proc. Natl. Acad. Sci. USA, 105 (2008) 18675-18680.

[20] T. Sekitani, T. Yokota, U. Zschieschang, H. Klauk, S. Bauer, K. Takeuchi, M. Takamiya, T. Sakurai, T. Someya, Organic Nonvolatile Memory Transistors for Flexible Sensor Arrays, Science 326 (2009) 1516-1519.

[21] D. Ellis, M. Eckhoff, V.D. Neff, Electrochromism in the mixed-valence hexacyanides. 1. Voltammetric and spectral studies of the oxidation and reduction of thin films of Prussian blue, J. Phys. Chem. 85 (1981) 1225-1231.

[22] K. Itaya, T. Ataka, S. Toshima, Spectroelectrochemistry and electrochemical preparation method of Prussian blue modified electrodes, J. Am. Chem. Soc. 104 (1982) 47674772.

[23] R.J. Mortimer, Electrochromic materials, Chem. Soc. Rev. 26 (1997) 147-156.

[24] K. Itaya, H. Akahoshi, S. Toshima, Polymer-Modified Electrodes II. Spectroelectrochemical Properties of a Ligand (Bathophenanthroline Disulfonic Acid) Bound to Polyelectrolytes on Electrodes and the Use of the Modified Electrodes for an Electrochromic Display Device, J. Electrochem. Soc. 129 (1982) 762-767.

[25] H. Kellawi, D.R. Rosseinsky, Electrochemical bichromic behaviour of ferric ferrocyanide (Prussian Blue) in thin film redox processes, J. Electroanal. Chem. 131 (1982) $373-376$

[26] B.J. Feldman, O.R. Melroy, Ion flux during electrochemical charging of Prussian Blue films, J. Electroanal. Chem. 234 (1987) 213-227.

[27] P.J. Kulesza, Solid-state electrochemistry of iron hexacyanoferrate (Prussian Blue type) powders, J. Electroanal. Chem. 289 (1990) 103-116.

[28] J.J. García-Jareño, J. Navarro-Laboulais, F. Vicente, Charge transport in prussian blue films deposited on ITO electrodes, Electrochim. Acta 41 (1996) 835-841. 
[29] J.J. García-Jareño, A. Sanmatías, F. Vicente, C. Gabrielli, M. Keddam, H. Perrot, Study of Prussian Blue (PB) films by ac-electrogravimetry: influence of PB morphology on ions movement, Electrochim. Acta 45 (2000) 3765-3776.

[30] J. Agrisuelas, C. Gabrielli, J.J. García-Jareño, D. Giménez-Romero, J. Gregori, H. Perrot, F. Vicente, Usefulness of F(dm/dQ) Function for Elucidating the Ions Role in PB Films, J. Electrochem. Soc. 154 (2007) F134-F140.

[31] G. Sauerbrey, The use of a quartz crystal oscillator for weighing thin layers and microweighing applications, Z. Phys., 155 (1959) 206-222.

[32] M.D. Levi, G. Salitra, N. Levy, D. Aurbach, J. Maier, Application of a quartz-crystal microbalance to measure ionic fluxes in microporous carbons for energy storage, Nature Mater. 8 (2009) 872-875.

[33] A.R. Hillman, The EQCM: electrogravimetry with a light touch. J. Solid State Electrochem. 15 (2011) 1647-1660.

[34] W.Y. Tsai, P.L. Taberna, P. Simon, Electrochemical quartz crystal microbalance (EQCM) study of ion dynamics in nanoporous carbons, J. Am. Chem. Soc. 136 (2014) 8722-8728.

[35] M.D. Levi, L. Daikhin, D. Aurbach, V. Presser, M.D. Levi, L. Daikhin, D. Aurbach, V. Presser, Quartz crystal microbalance with dissipation monitoring (EQCM-D) for in-situ studies of electrodes for supercapacitors and batteries: A mini-review. Electrochem. Comm. 67 (2016) $16-21$

[36] K. Kwon, F.P. Kong, F. McLarnon, J.W. Evans, Characterization of the SEI on a carbon film electrode by combined EQCM and spectroscopic ellipsometry. J. Electrochem. Soc. 150 (2003) A229-A233.

[37] Z. Yang, M.C. Dixon, R.A. Erck, L. Trahey, Quantification of the mass and viscoelasticity of interfacial films on tin anodes using EQCM-D, ACS Appl. Mater. Interfaces 7 (2015) 2658526594. 
[38] M.D. Levi, S. Sigalov, D. Aurbach, L. Daikhin, In situ electro-chemical quartz crystal admittance methodology for tracking compositional and mechanical changes in porous carbon elec-trodes, J. Phys. Chem C 117 (2013) 14876-14889.

[39] A. Bund, O. Schneider, V. Dehnke, Combining AFM and EQCM for the in situ investigation of surface roughness effects during electrochemical metal depositions, Phys. Chem. Chem. Phys. 4 (2002) 3552-3554.

[40] F. Marchini, S. Herrera, W. Torres, A. Y. Tesio, F. J. Williams, E. J. Calvo, Surface Study of Lithium-Air Battery Oxygen Cathodes in Different Solvent-Electrolyte pairs, Langmuir 31 (2015) 9236-9545.

[41] E. Nossol, A.J.G. Zarbin, A simple and innovative route to prepare a novel carbon nanotube/Prussian Blue electrode and its utilization as a highly sensitive $\mathrm{H}_{2} \mathrm{O}_{2}$ amperometric sensor, Adv. Funct. Mater. 19 (2009) 3980-3986.

[42] E. Nossol, V.H.R. Souza, A.J.G. Zarbin, Carbon nanotube/Prussian blue thin films as cathodes for flexible, transparent and ITO-free potassium secondary battery, J. Colloid Interface Sci. 478 (2016) 107-116.

[43] E. Nossol, A. J. G. Zarbin, Electrochromic properties of carbon nanotubes/Prussian blue nanocomposite films, Sol. Energy Mater Sol. Cells 109 (2013) 109 40-46.

[44] C. Gabrielli, J.J. Garcia-Jareño, M. Keddam, H. Perrot, F. Vicente, AcElectrogravimetry Study of Electroactive Thin Films. I. Application to Prussian Blue, J. Phys. Chem. B 106 (2002) 3182-3191.

[45] C. Gabrielli, J.J. Garcia-Jareño, M. Keddam, H. Perrot, F. Vicente, AcElectrogravimetry Study of Electroactive Thin Films. II. Application to Polypyrrole, J. Phys. Chem. B 106 (2002) 3192-3201.

[46] C.R. Arias, C. Debiemme-Chouvy, C. Gabrielli, C. Laberty-Robert, A. Pailleret, H. Perrot, O. Sel, New Insights into Pseudocapacitive Charge-Storage Mechanisms in Li- 
Birnessite Type $\mathrm{MnO}_{2}$ Monitored by Fast Quartz Crystal Microbalance Methods, J. Phys. Chem. C 118 (2014) 26551-26559.

[47] F. Razzaghi, C. Debiemme-Chouvy, F. Pillier, H. Perrot, O. Sel, Ion intercalation dynamics of electrosynthesized mesoporous $\mathrm{WO}_{3}$ thin films studied by multi-scale coupled electrogravimetric methods, Phys. Chem. Chem. Phys. 17 (2015) 14773-14787.

[48] S. Bourkane, C. Gabrielli, M. Keddam, Kinetic study of electrode processes by ac quartz electrogravimetry, J. Electroanal. Chem. Interfacial Electrochem. 256 (1988) 471-475.

[49] To Thi Kim, L. 2009, Etude de films électroactifs par couplage de techniques électrochimique et gravimétrique. Application à la caractérisation de membranes à conduction protonique, Ph.D. Thesis, Université Pierre et Marie Curie, Paris, France.

[50] F. Escobar-Teran, A. Arnau, J.V. Garcia, Y. Jiménez, H. Perrot, O. Sel, Gravimetric and dynamic deconvolution of global EQCM response of carbon nanotube based electrodes by Acelectrogravimetry, Electrochem. Commun. 70 (2016) 73-77.

[51] C. Gabrielli, H. Perrot, in: M. Schlesinger (Ed), Modern Aspects of Electrochemistry, Vol 44, Springer New York, 2009, p 151.

[52] F. Escobar Teran, 2016, A new approach towards understanding the ion transfer dynamics in nanostructured carbon-based thin films for energy storage applications, Ph.D. Thesis, Université Pierre et Marie Curie, Paris, France

[53] H. Goubaa, F. Escobar-Teran, I. Ressam, W. Gao, A. El Kadib, I. T. Lucas, M. Raihane, M. Lahcini, H. Perrot, O. Sel, Dynamic Resolution of Ion Transfer in Electrochemically Reduced Graphene Oxides Revealed by Electrogravimetric Impedance, J. Phys. Chem. C 121 (2017) 9370-9380. 
